\title{
PILOT CROSS-SECTIONAL STUDY OF THREE ZOONOSES (LYME DISEASE, TULARAEMIA, LEPTOSPIROSIS) AMONG HEALTHY BLOOD DONORS IN EASTERN SLOVAKIA
}

\author{
L'ubica Zákutná1, Erik Dorko', Kvetoslava Rimárová', Marianna Kizeková2 \\ 'Department of Public Health and Hygiene, Faculty of Medicine, P. J. Šafárik University, Košice, Slovak Republic \\ 'Department of Occupational Medicine and Clinical Toxicology, Faculty of Medicine, P. J. Šafárik University and L. Pasteur University Hospital, \\ Košice, Slovak Republic
}

\section{SUMMARY}

Objective: The aim of the study was to determine the seroprevalence of three zoonotic infections among healthy blood donors/volunteers in Eastern Slovakia.

Methods: Sera from 124 blood donors were investigated for the presence of antibodies against Borrelia burgdorferi, Francisella tularensis and Leptospira pomona. The participants also completed the questionnaire about demographic, exposure and epidemiological characteristics. Two serological methods were used for the diagnosis: the enzyme linked protein A/G assay (ELPAGA) and the Western blot (WB). First, sera were screened by ELPAGA (except for leptospirosis).

Results: The observed seroprevalence was $15 \%$ for Lyme borreliosis (LB) and 4\% for tularaemia (TUL). The results were confirmed by WB. Positive lgG antibodies (WB method) were detected only in $1.6 \%$ of examined for LB and $0.8 \%$ for TUL. Our results did not identify any antibodies against Leptospira pomona agent in the examined healthy blood donors group.

Conclusions: ELPAGA seroprevalence for TUL was significantly higher in blood donors working in the agricultural area in the direct contact with hay, straw, manure, and agricultural land. Our outputs determine tick bite as a significant risk factor for LB. The study confirms the explosion of tick-borne diseases in the healthy population of people. The exposure risk for leptospirosis seems to be minimal.

Key words: Lyme disease, tularaemia, leptospirosis, seroprevalence, blood donors, Slovakia

Address for correspondence: E. Dorko, Department of Public Health and Hygiene, Faculty of Medicine, P. J. Šafárik University, Šrobárova 2, 04080 Košice, Slovak Republic. E-mail: erik.dorko@upjs.sk

\section{INTRODUCTION}

Zoonoses are communicable diseases transmitted from animals to humans. More than $60 \%$ of human infectious diseases are caused by pathogens shared with wild or domestic animals. Emerging zoonoses are a growing threat to global health (1).

Lyme borreliosis (LB) is the most prevalent tick-borne zoonosis in the northern hemisphere including Slovakia. It is caused by spirochetes belonging to the Borrelia burgdorferi (B.b.) sensu lato (s.l.) complex which are transmitted by ticks $(2,3)$. B. afzelii and B. garinii are the most common European circulating genospecies (4).

From the epidemiological reports of the Specialized State Health Institute in Banská Bystrica, it appears that the number of patients with LB in Slovakia has increased from 59 cases recorded in 1986 to 1,054 cases in 2010 (incidence 19.43/100,000). In the year 2011, 852 cases were reported (incidence 15.68/100,000) and in 2012, 754 cases (incidence 13.95/100,000) (5). In the Czech Republic, the reported average incidence per year was 40/100,000 (6).

The routine diagnosis of borreliosis in humans is based on the determination of the levels of specific antibodies with using the enzyme-linked immunosorbent assay (ELISA). If the first step is reactive, the immunoblotting is performed to confirm it. IgG antibodies appear in serum 6 weeks after the infection, they reach their peak level after 4 to 6 months and are detectable in serum for many years (7).

Tularaemia (TUL), also known as "rabbit fever", is a zoonosis caused by a gram-negative bacterium Francisella (F.) tularensis. TUL is typically found in animals, especially rodents, rabbits, and hares, it is usually a rural disease. F. tularensis is divided into four subspecies: tularensis, mediasiatica, holarctica, and novicida. The bacterium can be transmitted by an arthropod bite, ingestion, inhalation, or direct contact with infected tissues $(8,9)$.

TUL was reported from many countries of northern hemisphere. In the Slovak Republic within the period of 1997-2008, the reported average incidence was $0.71 / 100,000$ (8). In 2011, only 5 cases $(0.10 / 100,000)$ and in 2012,8 cases of tularaemia $(0.15 / 100,000)$ were reported in the Slovak Republic (5). In the Czech Republic, the average incidence per year is similar in the range of $0.5-1.0 / 100,000$ (6).

The screening assay ELISA and then the Western blot (WB) have been established in recent years for the identification of tularaemia antibodies. Antibodies appear around 2 to 3 weeks after infection and antibodies may be detected years after the patient's cure (9). 
Leptospirosis (LEP) is a zoonosis found worldwide, the main reservoir of which is the rat. The genus Leptospira includes 20 Leptospira (L.) species and more than 300 serovars. Humans become infected most commonly through occupational, recreational or domestic contact of skin with the urine of infected animals, either directly or via contaminated water or soil (10).

The number of severe human cases worldwide is estimated above 500,000. Incidences range from $0.1-1 / 100,000$ per year in temperate climates, $10-100 / 100,000$ per year in the humid tropic climate, to over $100 / 100,000$ per year during outbreaks and in high-exposure risk groups (11). Incidence in the Slovak Republic is about $0.4 / 100,000$ every year (6). In 2011, only 7 cases of leptospirosis were reported $(0.13 / 100,000)$ and in 2012 , the incidence $0.15 / 100,000$ was confirmed (5). The average incidence per year in the Czech Republic is 0.16-0.40/100,000 (6).

ELISA and the microscopic agglutination are the generally used laboratory methods (11). The only proof of asymptomatic infection is specific anti-Leptospira antibodies. Thus, the serological response rate of the examined population to Leptospira antigen may be regarded as an indicator of the prior contact with these bacteria and the degree of exposure (10).

According to the WHO recommendations (12), screening of all blood donors should be mandatory for the following infections: HIV, hepatitis B and C, and syphilis. Screening for other infections (malaria, Chagas disease) should be based on the local epidemiological evidence. LB, TUL and LEP belong to the insignificant transfusion-transmissible infections that may be transmitted if the blood donor is currently infected and has a high level of the infectious agent in the bloodstream at the time of donation. Diagnosis of the previously mentioned diseases is not performed as a part of general laboratory blood donor screening due to costly and time demanding procedure. But serologic screening of healthy population is important for risk assessment of transmitted diseases in blood donors as well as in blood recipients.

Missing epidemiological data in endemic countries complicate an appropriate risk assessment necessary for the public health authorities. Our objectives were also to conduct a pilot survey on a selected sample of healthy blood donors in Eastern Slovakia to assess the seroprevalence of three selected zoonotic diseases and to identify potential risk factors for blood recipients.

\section{MATERIAL AND METHODS}

\section{Sample Characteristics}

A pilot cross-sectional study included serum samples and questionnaires from 124 healthy blood donors/volunteers from Eastern Slovakia. Before data and blood sample collection informed consent was obtained from each examined person.

\section{Serum Samples}

Venous blood samples were collected from each donor. Sera were separated and stored at $-20^{\circ} \mathrm{C}$ for use of serological assays. Samples were taken in 2011 during winter and spring period.

Specific antibodies $\operatorname{IgG}$ against $B$. b. sensu lato, F. tularensis and L.interrogans were detected in all samples using immu- noenzymatic methods - the Enzyme linked protein A/G assay (ELPAGA) (except for leptospirosis for limitation antigen) and the Western blot (WB). Both serological tests were non-commercial, in-house tests.

\section{Antigens}

A mixture of local whole cell antigens (WCL) species $B$. garinii and B. afzelii 1:1 was used for the serology of LB, WCL of live vaccine strain (LVS) F.tularensis holarctica enriched $17 \mathrm{kDa}$ LPN recombinant protein for TUL, whole cell antigen (WCL) L. interrogans serovar pomona enriched with ompL1 (17 kDa) leptospiral recombinant protein for leptospirosis.

ELPAGA was performed as described by Bhide et al. (13). 100 $\mu \mathrm{g}$ antigens (depending on investigated pathogen) were used to coat microtiter well. Nonspecific binding sites were blocked by addition of $1 \%$ bovine serum albumin (Sigma, USA). Diluted human serum samples, positive and negative control sera were added in duplicate to the wells. After incubation for $1 \mathrm{~h}$ at $37^{\circ} \mathrm{C}$, plates were washed with phosphate buffer saline plus Tween 20 (PBST20). Protein G conjugated with horse radish peroxidase (HRP) was added in each well. Plates were incubated for $1 \mathrm{~h}$ at $37^{\circ} \mathrm{C}$ and washed with PBST20. Substrate was added and plates were incubated for $25 \mathrm{~min}$. Absorbance was measured at $405 \mathrm{~nm}$.

\section{WB}

Different antigens were fractionated by non-reducing SDSPAGE, immunoblotted and the membranes were cut in strips, which were incubated 1 hour in TTBS buffer with $2 \%$ skim milk. Strips were then incubated for overnight in diluted serum samples. To detect bound IgG antibodies on antigens, strips were incubated for 1 hour with protein G HRP conjugate. After 5 washings, enhanced chemiluminescence substrate was added to the strips and incubated for $5 \mathrm{~min}$. Signals were captured on X-ray film (Kodak).

\section{Questionnaires}

The questionnaire contained demographic data: gender, age, residence; and epidemiological and occupational data: occupation (agricultural section, other section), occasional work that involved contact with straw, hay, soil, or manure, contact with other animal products, work in dusty environment, frequent outdoor activities such as gardening, working in the field, hiking, hunting, staying at the cottage, stay in the forest, tick bite, contact with animals.

\section{Statistical Methods}

Study results from ELPAGA serology were presented as Odds Ratios (OR) with 95\% confidence interval (CI). The statistically significant level was considered $p<0.05$. Epi-Info version 7 software was used for calculations. Only positive and negative serological tests were accepted in statistical analysis. Equivocal serological results were not included in the analysis. As seropositivity of leptospirosis was not confirmed, we did not describe relationship of risk factors for leptospirosis positivity in the results. 


\section{RESULTS}

\section{Characteristics of the Investigated Group}

In the year 2011, we collected sample of 124 healthy blood donors/volunteers. Cross-sectional study included 77 males and 47 females, predominantly in the productive age up to 30 years $(54.8 \%)$, $30-50$ years $(35.5 \%)$, over 50 years $(9.7 \%)$. Urban residents created $66.1 \%$ of the sample, $33.9 \%$ subjects resided in rural areas.

Occupational exposure was reported by $23.8 \%$ of participants. Contact with hay and straw was confirmed in $25 \%$ of participants, $36.3 \%$ participants had contacts with soil, $22.6 \%$ had contacts with manure, $31.5 \%$ with animal leather, fur, or feather, $31.5 \%$ had contact with other animal products (wool, hair, droppings, meat, milk, blood, urine).

In terms of outdoor activities, subjects reported following activities: $41.9 \%$ of respondents reported gardening, $25.8 \%$ touristic and hiking activities, $12.9 \%$ staying at the cottage, $7.3 \%$ hunting activities, and $9.7 \%$ working in the field.

Most of the blood donors (73.9\%) visited the forest occasionally, $14.3 \%$ went to the forest often and $11.8 \%$ did not visit the forest. History of the tick bite was reported in $37.3 \%$ of respondents. More than half of participants $(53.2 \%)$ had contact with animals (Table 1).

Table 1. General exposure characteristics of examined subjects $(N=124)$

\begin{tabular}{|c|c|c|c|}
\hline \multirow{2}{*}{\multicolumn{2}{|c|}{ Risk factors/characteristic }} & \multicolumn{2}{|c|}{ Subjects } \\
\hline & & \multirow{2}{*}{$\begin{array}{c}\text { Numbers (n) } \\
78\end{array}$} & \multirow{2}{*}{$\begin{array}{c}\% \\
66.1\end{array}$} \\
\hline Recidona & urban & & \\
\hline Rediuetile & rural & 40 & 33.9 \\
\hline \multirow{2}{*}{ Occupation } & exposed (agriculture) & 24 & 23.8 \\
\hline & non exposed (other sector) & 77 & 76.2 \\
\hline \multirow{2}{*}{ Gender } & male & 77 & 62.1 \\
\hline & female & 47 & 37.9 \\
\hline \multirow{2}{*}{ Age } & younger (up to 30 years) & 68 & 54.8 \\
\hline & middle and older (over 30 years) & 56 & 45.2 \\
\hline \multirow{2}{*}{ Contact with soil } & yes & 45 & 36.3 \\
\hline & no & 79 & 63.7 \\
\hline \multirow{2}{*}{ Contact with hay, straw } & yes & 31 & 25.0 \\
\hline & no & 93 & 75.0 \\
\hline \multirow{2}{*}{ Contact with manure } & yes & 22 & 17.7 \\
\hline & no & 102 & 82.3 \\
\hline \multirow{2}{*}{ Contact with animal leather, fur, feather } & yes & 28 & 22.6 \\
\hline & no & 96 & 77.4 \\
\hline \multirow{2}{*}{ Contact with other animal products } & yes (wool, hair, blood etc.) & 39 & 31.5 \\
\hline & no & 85 & 68.5 \\
\hline \multirow{2}{*}{ Gardening } & yes & 52 & 41.9 \\
\hline & no & 72 & 58.1 \\
\hline \multirow{2}{*}{ Working in the field } & yes (agricultural field exposure) & 12 & 9.7 \\
\hline & no & 112 & 90.3 \\
\hline \multirow{2}{*}{ Hiking } & yes & 32 & 25.8 \\
\hline & no & 92 & 74.2 \\
\hline \multirow{2}{*}{ Hunting } & yes & 9 & 7.3 \\
\hline & no & 115 & 92.7 \\
\hline \multirow{2}{*}{ Stay at the cottage } & yes & 16 & 12.9 \\
\hline & no & 108 & 87.1 \\
\hline \multirow{2}{*}{ Stay in the forests } & yes (occasional or frequent) & 14 & 11.8 \\
\hline & no & 105 & 88.2 \\
\hline \multirow{2}{*}{ Contact with animals } & yes & 66 & 53.2 \\
\hline & no & 58 & 46.8 \\
\hline \multirow{2}{*}{ Tick bite } & yes & 44 & 37.3 \\
\hline & no & 74 & 62.7 \\
\hline
\end{tabular}




\section{Serological Results}

Sera were first screened by ELPAGA (except for leptospirosis). The observed seroprevalence using this method was $15 \%(n=19)$ for $\mathrm{LB}, 4 \%(\mathrm{n}=5)$ for TUL. All samples were then tested by WB. Positive IgG antibodies were detected only in $1.6 \%(n=2)$ of all 124 examined for LB and $0.8 \%(n=1)$ for TUL. These sera were also positive in the first test. IgG antibodies against $L$. interrogans were not present (Table 2).

\section{Epidemiological Results}

Table 3 shows calculated OR for the potential risk factors for LB and TUL seropositivity detected by ELPAGA in blood donors. Risk factors are stratified for residence, occupation, sex, age group, contact with soil, hay and straw, manure, or animal leather, gardening, agricultural field exposure, hiking, hunting, staying at the cottage, stay in the forest, presence of home animals, and tick bite.

\section{Seroprevalence of Lyme Disease and Risk Factors}

A significantly higher seroprevalence was observed in blood donors with the history of tick bite $(\mathrm{OR}=3.77, \mathrm{CI}=1.02-13.78$, $\mathrm{p}=0.04$ ) than without bite (Table 3 ). Therefore, our study confirmed history of tick bite as important significant factor for LB seropositivity.

The OR of being seropositive was two times higher for females $(\mathrm{OR}=2.04, \mathrm{CI}=0.76-5.47, \mathrm{p}=0.15)$ compared to males and in persons having home animals $(\mathrm{OR}=2.13, \mathrm{CI}=0.75-6.01, \mathrm{p}=0.15)$. Slightly increased ORs were found in blood donors among urban residents, donors with occupational exposure in agriculture, with agricultural field exposure and in tourists, while in case of other factors (age, contact with soil, gardening, hunting, staying at the cottage and forest) ORs were low. However, none of these estimates reached the level of statistical significance (Table 3).

WB confirmed only 2 positive samples in our group, both subjects were from the younger age group (30-50 years; 1 male, 1 female), they reported urban life, without occupational expo-

Table 2. Numbers and percentages of seropositivity for $L B$, $T U L$ and $L E P(N=124)$

\begin{tabular}{|l|c|c|c|c|c|c|}
\hline \multirow{2}{*}{ Methods } & \multicolumn{9}{|c|}{ Disease } \\
\cline { 2 - 7 } & \multicolumn{2}{|c|}{ LB } & \multicolumn{2}{c|}{ TUL } & \multicolumn{2}{c|}{ LEP } \\
\cline { 2 - 8 } & $\mathrm{n}$ & $\%$ & $\mathrm{n}$ & $\%$ & $\mathrm{n}$ & not measured \\
\hline ELPAGA positive & 19 & 15 & 5 & 4 & not measured measured & not measured \\
\hline ELPAGA negative & 105 & 85 & 119 & 0.8 & 0 & 0 \\
\hline WB positive & 2 & 1.6 & 1 & 99 & 124 & 100 \\
\hline WB negative & 122 & 98.4 & 123 & 96 & \\
\hline
\end{tabular}

Table 3. Results of OR of potential risk factors for seropositivity LB and TUL detected by ELPAGA in blood donors

\begin{tabular}{|l|c|c|c|c|c|c|}
\hline \multirow{2}{*}{ Risk factor } & \multicolumn{3}{|c}{ LB } & \multicolumn{3}{c|}{ TUL } \\
\cline { 2 - 7 } & OR & $95 \% \mathrm{Cl}$ & $\mathrm{p}$ & $\mathrm{OR}$ & $95 \%$ CI & $\mathrm{p}$ \\
\hline Residence urban/rural & 1.531 & $0.509-4.605$ & 0.448 & 3.081 & $0.493-19.243$ & 0.209 \\
\hline Occupational exp./nonexp. & 1.083 & $0.271-4.324$ & 0.910 & 10.857 & $1.073-109.84$ & $0.014^{*}$ \\
\hline Gender female/male & 2.042 & $0,762-5.471$ & 0.152 & 1.096 & $0.176-6.815$ & 0.921 \\
\hline Age younger/older & 0.701 & $0.264-1.869$ & 0.478 & 3.437 & $0.373-31.675$ & 0.250 \\
\hline Contact with soil yes/no & 0.416 & $0.129-1.342$ & 0.135 & 2.750 & $0.442-17.114$ & 0.262 \\
\hline Contact with hay, straw yes/no & - & - & - & 13.000 & $1.395-121.129$ & $0.005^{* *}$ \\
\hline Contact with manure yes/no & - & - & - & 7.894 & $1.235-50.473$ & 0.012 \\
\hline Contact with animal leather, fur, feather yes/no & - & - & - & 2.385 & $0.375-15.034$ & 0.346 \\
\hline Gardening yes/no & 0.440 & $0.148-1.312$ & 0.135 & 0.920 & $0.148-5.711$ & 0.928 \\
\hline Agricultural field exposure yes/no & 1.117 & $0.224-5.555$ & 0.892 & 7.267 & $1.083-48.721$ & $0.019^{*}$ \\
\hline Hiking yes/no & 1.402 & $0.484-4.064$ & 0.533 & 1.978 & $0.315-12.409$ & 0.460 \\
\hline Hunting yes/no & 0.674 & $0.079-5.719$ & 0.716 & 3.468 & $0.345-34.799$ & 0.264 \\
\hline Stay at the cottage yes/no & 0.765 & $0.159-3.674$ & 0.738 & - & - & - \\
\hline Stay in the forest yes/no & 0.6111 & $0.152-2.450$ & 0.485 & - & - & - \\
\hline Contact with animals yes/no & 2.125 & $0.751-6.015$ & 0.150 & 0.572 & $0.092-3.554$ & 0.547 \\
\hline Tick bite yes/no & 3.770 & $1.021-13.783$ & 0.035 & 0.550 & $0.055-5.460$ & 0.606 \\
\hline
\end{tabular}

${ }^{*} p<0.05,{ }^{* *} p<0.01$ 
sure and without outdoor activities. However, both of them had a positive history of tick bite and the female described also contact with animals, hay and straw.

\section{Tick Bite and Risk Factors}

Tick bites were evaluated as a significant factor for seroprevalence of LB. Our study focused also on the establishment of risk factors which are possible predictors of tick bite. There were recognized factors associated directly with tick bite. The results (Table 4) indicate that blood donors, who reported hiking, were significantly more likely to report tick bite $(\mathrm{OR}=4.77$, $\mathrm{CI}=1.99-11.43, \mathrm{p}=0.001)$ compared with non-hikers. Among subjects staying at the cottage, OR for tick bite probability was 4 times higher $(\mathrm{OR}=4.06, \mathrm{CI}=1.29-12.81, \mathrm{p}=0.012)$ when compared to the group not staying in the cottage. Participants living in urban areas, hunters and those that walk into the forest or are exposed to agricultural field had twice higher OR for risk of tick bite, however, the results were statistically insignificant.

\section{Seroprevalence of Tularaemia and Risk Factors}

Subjects with occupational exposure were 10.9 times likely to be seropositive $(\mathrm{OR}=10.857, \mathrm{CI}=1.073-109.84, \mathrm{p}=0.014)$ compared with the group without the occupational exposure. Also, some factors were significantly associated with seropositivity: contact with hay and straw $(\mathrm{OR}=13.000, \mathrm{CI}=1.395-121.129, \mathrm{p}=0.005)$, contact with manure $(\mathrm{OR}=7.894, \mathrm{CI}=1.234-50.473, \mathrm{p}=0.012)$. Our study confirmed also higher risk for subjects with agricultural field exposure $(\mathrm{OR}=7.267, \mathrm{CI}=1.083-48.721, \mathrm{p}=0.019)$. Other evaluated factors (residence, gender, age, contact with soil, animal leather, fur, feather, or animals, tick bite and outdoors activities gardening, hiking, hunting) were statistically insignificant (Table 3).

\section{Seroprevalence of Leptospirosis}

Seroprevalence of leptospirosis was detected only with WB and all 124 blood samples were negative. There was no possibility to determine the association with risk factors.

\section{DISCUSSION}

\section{Lyme Boreliosis}

We observed $15 \%(n=19)$ seroprevalence of B. burgdorferi among investigated blood donors using ELPAGA test, which is the version of routinely used ELISA method. Only $1.6 \%(n=2)$ subjects were serologicaly positive for LB with the use of WB. Serological tests comprise indirect fluorescent-antibody assay (IFA), ELISA and WB seems to be very useful. Heterogenity of the agent of LB as well as differences in methods applied in the preparation of antigens and in tests procedures can cause significant discrepancies between the results of serological examinations obtained in different laboratories, which was similar to the seroprevalence rates in blood donors reported by Bazovská et al. (14) from Western Slovakia. It was proven in the serum of 250 blood donors by 3 different screening tests in $4.4-15.6 \%$ of all persons, and by using WB in $12.8 \%$. These results are higher than ours. The infestation of ticks with borreliae was found in the whole territory of Slovakia, however, the infestation and LB incidence seems to be higher in the western regions.

Studies on the adult population of Europe showed that frequency of specific IgG antibodies for B. burgdorferi s.l. varied. We have noticed few publications focused on the exposed (forestry workers, farmers, outdoor workers etc.) in comparison to the nonexposed subjects (especially blood donors), e.g. by Bartůnek et al. (15) $10 \%$ vs. $12.7 \%$ in the Czech Republic, Zwoliński et al. (16) $32 \%$ vs. $7.1 \%$, Chmielewska-Badora et. al. (2) $45.6 \%$ vs. $12.5 \%$ in Poland, and others.

The high infestation of Ixodes ricinus ticks by B.b.s.l. was confirmed by studies of other authors (17). In our study, we showed 3.8 times higher likelihood to be positive in ELPAGA among blood donors with anamnesis of tick bite $(\mathrm{p}=0.035)$. Both subjects that were tick bitten, were seropositive in confirmatory WB test as well. In some studies, this association remained independent (18) while in others has not been confirmed (19). We recorded risk factor for the tick bite in some recreational activities. Hiking and staying at the cottage were directly $(p=0.001$ and $p=0.012)$ associated with tick bite, but not with seroprevalence.

Table 4. Results of ORs for tick bites risk factors

\begin{tabular}{|l|c|c|c|}
\hline Factor & OR & $95 \%$ Cl & p \\
\hline Residence urban/rural & 2.018 & $0.8567-4.7565$ & 0.106 \\
\hline Occupational exp./nonexp. & 1.846 & $0.7052-4.8333$ & 0.211 \\
\hline Gender female/male & 1.128 & $0.5214-2.4393$ & 0.760 \\
\hline Age younger/older & 1.247 & $0.5884-2.6410$ & 0.566 \\
\hline Contact with soil yes/no & 1.583 & $0.733-3.419$ & 0.242 \\
\hline Contact with manure yes/no & 1.473 & $0.557-3.897$ & 0.436 \\
\hline Gardening yes/no & 1.589 & $0.745-3.390$ & 0.231 \\
\hline Agricultural field exposure yes/no & 2.179 & $0.624-7.614$ & 0.216 \\
\hline Hiking yes/no & 4.773 & $1.993-11.428$ & $0.001^{* * *}$ \\
\hline Hunting yes/no & 2.367 & $0.504-11.109$ & 0.265 \\
\hline Stay at the cottage yes/no & 4.059 & $1.286-12.811$ & $0.012^{*}$ \\
\hline Stay in the forest yes/no & 2.351 & $0.806-6.856$ & 0.112 \\
\hline Contact with animals yes/no & 1.505 & $0.704-3.214$ & 0.292 \\
\hline
\end{tabular}


Others risk factors for B. burgdorferi seropositivity were identified as insignificant. However, different studies confirmed the association between the occurrence of antibodies and rural life, exposed occupation - forestry workers, farmers $(4,18)$, male gender $(3,4)$, increasing age $(4,20)$, outdoor activities, e.g. gardening (18), contact with animals - especially cats owners in households of German children (3).

\section{Tularaemia}

The seropositivity was detected by the method ELPAGA in $4 \%(n=5)$ and by the WB test it was confirmed in $0.8 \%(n=1)$ of investigated blood donors.

In the study of blood donors from Western Slovakia (19), the observed presence of antibodies against F.tularensis was also $4 \%$, but by using an agglutination test kit, which has a lower specificity than ours. E.g. in Germany, Jenzora et al. (9) described with the standard ELISA and WB an elevated risk for hunters to be seropositive (1.7\%) compared to cross-sectional study among healthy German population (0.2\%). In Austria, Deutz et al. (21) also showed that hunters are particularly exposed to zoonotic pathogens, for TUL it was 3\%. In our study hunters did not appear statistically significant, which can be caused by the low number of hunters in our group $(n=9)$.

According to our findings, the workers in the agricultural sector were approximately 10 times more likely to be positive compared to those working in other sectors. Although we had a low number of positive subjects, the presence of antibodies was demonstrated in people exposed to hay, straw, manure, or agricultural land with significant $p<0.05$. One woman was seropositive for both tests, she was also a worker in the agriculture in contact with those products. The results correlate with observations of Guryčová et al. (8), who described the change in the epidemiological characteristics of TUL in Slovakia. While in the past there was a transmission of TUL by the hares, the proportion of infections from other sources has been rising recently - most often during outdoor activities, when the feeding stuff, bedding, hay, or straw could be contaminated by excretes of small rodents. In the years 1997-2008, TUL was recorded most often in the population of rural areas. The rural population, particularly individuals who spend a lot of time in endemic areas such as farmers, hunters, forestry workers, and vacationers in nature are at highest risk of infection of TUL (22).

Clark et al. (23) in Azerbaijan tested village volunteers with the prevalence of $15.5 \%$, while they observed the risk factor - the frequent occurrence of rodents near the houses. In our questionnaires, there was no defined contact with the rodents, but only the contact with animals generally. However, this factor does not seem to be important.

\section{Leptospirosis}

None of the subjects examined had antibodies IgG to L. interrogans. Monno et al. (24) presented the same negative seroprevalence in blood donors and in the workers exposed to farm animals in Southern Italy. However, in Northern and Central Italy, 5.6\% of humans were seropositive. Wasiński et al (10) showed 3-9.3\% positivity in people exposed and non-exposed to floods in Eastern Poland. Prevalence of anti-leptospira antibodies in the U.S. Army blood bank donors in Hawaii was 1.4\% (25).
The territory of Slovakia is known for the occurrence of active natural foci of leptospirosis. This is evidenced by a study of Bazovská et al. (19), where the incidence of $1 \%$ of anti-leptospira antibodies in blood donors from Western Slovakia was proven. Although the seropositivity was not detected in the investigated group from Eastern Slovakia, the risk of infection due to the occurrence of natural outbreaks is possible also in occupationally and recreationally exposed Slovak population.

Our study investigated antibodies against frequently occurring serovar L. pomona. When using multiple antigens serovars, the results would be possibly different. In Mexico, Gavaldón et al. (26) analysed 206 adult blood donors against seven serovars of L. interrogans. A total of $7 \%$ were positive for L. sherman, canicola, pyrogens, pomona, icterohaemorrhagiae. On the other hand, e.g. in Japan, using all six serotypes showed negative results (27).

\section{CONCLUSION}

Our results confirmed that the following risk factors such as tick bites, occupation, contact with straw, hay, manure, field work, and outdoor activities (hiking and staying at the cottage) are significantly associated with the presence of positive specific antibodies against investigated diseases. Study results support recommendations for maintaining preventive measures in occupational and other outside activities (tick bite protection measures and health and safety at work).

Seroepidemiological studies on healthy population are important to define the extent of epidemiologic risk in certain areas and risk resulting from specific activities. Preventive measures based on results of laboratory screening among healthy blood donors could support health protection of general population living in certain areas as well as protection of individuals exposed to risk factors.

\section{Acknowledgements}

This work was supported by project VVGS - 3/GSD/2012 and Grant VEGA No. 1/0198/13 of the Ministry of Education, Science, Research and Sport of the Slovak Republic.

\section{REFERENCES}

1. Karesh WB, Dobson A, Lloyd-Smith JO, Lubroth J, Dixon MA, Bennett $\mathrm{M}$, et al. Ecology of zoonoses: natural and unnatural histories. Lancet. 2012 Dec 1;380(9857):1936-45.

2. Chmielewska-Badora J, Moniuszko A, Żukiewicz-Sobczak W, Zwoliński J, Piątek J, Pancewicz S. Serological survey in persons occupationally exposed to tick-borne pathogens in cases of co-infections with Borrelia burgdorferi, Anaplasma phagocytophilum, Bartonella spp. and Babesia microti. Ann Agric Environ Med. 2012;19(2):271-4.

3. Dehnert M, Fingerle V, Klier C, Talaska T, Schlaud M, Krause G, et al. Seropositivity of Lyme borreliosis and associated risk factors: a population-based study in children and adolescents in Germany (KiGGS). PLoS One. 2012;7(8):e41321. doi: 10.1371/journal.pone.0041321.

4. Buczek A, Rudek A, Bartosik K, Szymanska J, Wojcik-Fatla A. Seroepidemiological study of Lyme borreliosis among forestry workers in southern Poland. Ann Agric Environ Med. 2009 Dec;16(2):257-61.

5. Epidemiological information system. Annual reports [Internet]. Bratislava: Public Health Autority of the Slovak Republic; 2006 [cited 2014 Jun 2]. Available from: http://www.epis.sk/InformacnaCast/Publikacie/ VyrocneSpravy.aspx. (In Slovak.)

6. World Health Organization. CISID home [Internet]. Geneva: WHO; 2014 [cited 2014 Jun 2]. Available from: http://data.euro.who.int/cisid. 
7. Biesiada G, Czepiel J, Leśniak MR, Garlicki A, Mach T. Lyme disease: review. Arch Med Sci. 2012 Dec 20;8(6):978-82.

8. Guryčová D, Tináková K, Výrosteková V, Gacíková E. The incidence of tularemia in Slovakia in 1997-2008. Epidemiol Mikrobiol Imunol. 2010 Feb;59(1):39-44. (In Slovak.)

9. Jenzora A, Jansen A, Ranisch H, Lierz M, Wichmann O, Grunow R. Seroprevalence study of Francisella tularensis among hunters in Germany. FEMS Immunol Med Microbiol. 2008 Jul;53(2):183-9.

10. Wasiński B, Sroka J, Wójcik-Fatla A, Zając V, Cisak E, Knap JP, et al. Seroprevalence of leptospirosis in rural populations inhabiting areas exposed and not exposed to floods in eastern Poland. Ann Agric Environ Med. 2012;19(2):285-8.

11. Musso D, La Scola B. Laboratory diagnosis of leptospirosis: a challenge. J Microbiol Immunol Infect. 2013 Aug;46(4):245-52.

12. Screening donated blood for transfusion-transmissible infections: recommendations [Internet]. Geneva: WHO; 2009 [cited 2014 Jun 2]. Available from: http://apps.who.int/iris/bitstream/10665/44202/1/9789241547888 eng.pdf?ua $=1$.

13. Bhide MR, Curlik J, Travnicek M, Lazar P. Protein A/G dependent ELISA a promising diagnostic tool in Lyme disease seroprevalence in game animals and hunting dogs. Comp Immunol Microbiol Infect Dis. 2004 May;27(3):191-9.

14. Bazovská S, Macháčová E, Špaleková M, Kontrosová S. Reported incidence of Lyme disease in Slovakia and antibodies to B. burgdorferi antigens detected in healthy population. Bratisl Lek Listy. 2005;106(89):270-3.

15. Bartůněk P, Goričan K, Veiser T, Mrázek V, Vařejka P, Hulínská D. The information value of detection of borrelia antibodies in the healthy blood donors and in the population at risk. Cas Lek Cesk. 2007;146(7):603-7. (In Czech.)

16. Zwoliński J, Chmielewska-Badora J, Cisak E, Buczek A, Dutkiewicz J. Prevalence of antibodies to Anaplasma phagocytophilum and Borrelia burgdorferi in forestry workers from the Lublin region. Wiad Parazytol. 2004;50(2):221-7. (In Polish.)

17. Drgonová M, Řeháček J. Prevalence of Lyme borrelia in ticks in Bratislava, Slovak Republic. Cent Eur J Public Health. 1995 Aug;3(3):134-7.

18. Cinco M, Barbone F, Grazia Ciufolini M, Mascioli M, Anguero Rosenfeld M, Stefanel P, et al. Seroprevalence of tick-borne infections in forestry rangers from northeastern Italy. Clin Microbiol Infect. 2004 Dec;10(12):1056-61.

19. Bazovská S, Guryčová D, Výrosteková V, Jareková J, Bakoss P, Macháčová E, et al. Antibodies against the causative agents of some natural focal infections in blood donor sera from Western Slovakia. Epidemiol Mikrobiol Imunol. 2010;59(4):168-71.

20. Arteaga F, Golightly MG, Garcia Perez A, Barral M, Anda P, GarciaMonco JC. Disparity between serological reactivity to Borrelia burgdorferi and evidence of past disease in a high-risk group. Clin Infect Dis. 1998 Nov;27(5):1210-3.

21. Deutz A, Fuchs K, Schuller W, Nowotny N, Auer H, Aspöck H, et al. Seroepidemiological studies of zoonotic infections in hunters in southeastern Austria - prevalences, risk factors, and preventive methods. Berl Munch Tierarztl Wochenschr. 2003 Jul-Aug;116(7-8):306-11. (In German.)

22. Ellis J, Oyston PC, Green M, Titball RW. Tularemia. Clin Microbiol Rev. 2002 Oct;15(4):631-46.

23. Clark DV, Ismailov A, Seyidova E, Hajiyeva A, Bakhishova S, Hajiyev $\mathrm{H}$, et al. Seroprevalence of tularemia in rural Azerbaijan. Vector Borne Zoonotic Dis. 2012 Jul;12(7):558-63.

24. Monno R, Fumarola L, Trerotoli P, Cavone D, Giannelli G, Rizzo C, et al. Seroprevalence of Q fever, brucellosis and leptospirosis in farmers and agricultural workers in Bari, Southern Italy. Ann Agric Environ Med. 2009 Dec;16(2):205-9.

25. Lettieri C, Moon J, Hickey P, Gray M, Berg B, Hospenthal D. Prevalence of leptospira antibodies in U.S. Army blood bank donors in Hawaii. Mil Med. 2004 Sep;169(9):687-90.

26. Gavaldón DG, Cisneros MA, Rojas N, Moles-Cervantes LP. Significance of human leptospirosis in Mexico. Detection of Leptospira antibodies in a blood donor population. Gac Med Mex. 1995 May-Jun;131(3):289-92. (In Spanish.)

27. Tajima K, Kozawa K, Suzuki T, Sone T. A study of seroprevalence of leptospirosis in Gunma Prefecture, 2010. Nihon Koshu Eisei Zasshi. 2012 Nov;59(11):833-7. (In Japanese.)

Received June 2, 2014 Accepted in revised form March 25, 2015 